\title{
A rare cause of gastric obstruction: Lighters swallowing
}

\author{
Ulas Aday, Ali Tardu, Mehmet Ali Yagci, Huseyin Yonder \\ Department of General Surgery, Inonu University Faculty of Medicine, Malatya, Turkey
}

\begin{abstract}
The majority of swallowed foreign bodies are thrown spontaneously without causing complications in the digestive system. Multiple number of foreign bodies may be swallowed by psychiatric patients which delay diagnosis and increase the complication rate. Long and hard objects cannot pass through the pylorus, and may cause obstruction, ulceration, bleeding and perforation. Endoscopy is used as an effective method in such cases. An exploratory laparatomy was performed after unsuccessful endoscopic foreign object removal in a 28-year-old schizophrenic patient with gastric outlet obstruction due to multiple cigarette lighter swallowing. Ten lighters were removed from the stomach through gastrotomy and one more lighter was removed from the descending colon by milking through the anus. The aim of this paper is to discuss encountered difficulties in psychiatric patients who underwent surgery due to intake of foreign bodies.
\end{abstract}

Keywords: Foreign body; schizophrenia; stomach.

$\mathrm{T}$ hough swallowing foreign objects is seen in children, it is more frequently observed in elder people, mentally retarded group, prisoners, and patients with psychiatric disorder. Surgical treatment is applied in $1 \%$ of the patient group when endoscopic interventions remain adequate or complications develop [1]. Patients with psychosis like schizophrenia tend to swallow usually multiple foreign objects repetitively. Since the patients do not give history of swallowing foreign objects, diagnosis is delayed, and risk of complications increases [2].

In our study in a 28-year-old patient with the diagnosis of schizophrenia who developed gastric outlet obstruction has been presented in the light of current literature.

\section{CASE REPORT}

A 28-year-old male patient consulted to the emergency service with complaints of abdominal pain, nausea, and vomiting persisting for two days. His physical examination did not reveal any finding except for tenderness over epigastrium. He was diagnosed as schizophrenia, but he was not receiving antipsychotic drugs. His whole blood cell counts, and biochemical parameters were not remarkable. Multiple radiopaque images of foreign objects were seen in the stomach on his upright abdominal radiograms (Figure 1). His mother said that two years ago he swallowed a metal coin which was extracted using endoscopic intervention. The patient under- 


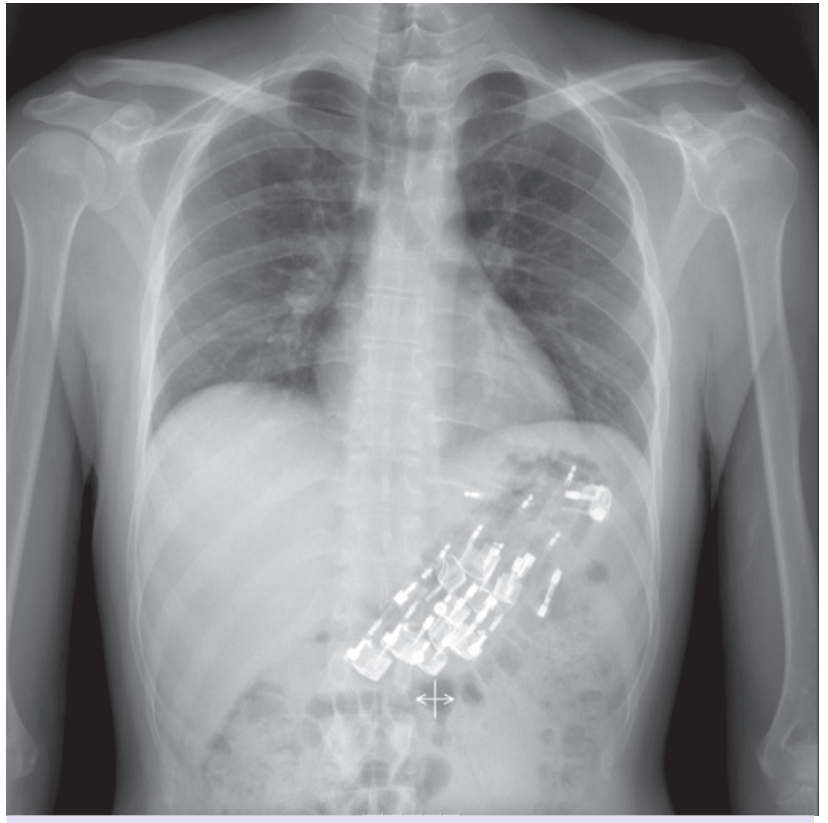

FIGURE 1. Multiple number of lighters in the stomach.

went gastrointestinal endoscopy on an emergency basis with the initial diagnosis of foreign object which caused pyloric obstruction Since the stomach was full of food remnants the ingested foreign objects could not be identified, and examination was repeated after 12 hours of fasting. During the second endoscopic procedure multiple number of lighters which filled the stomach almost completely were observed. Endoscopic removal of the lighters was attempted, however injury of the distal part of the esophagus necessitated termination of the procedure, and urgently open surgery was planned. Preoperatively, plain abdominal radiograms were obtained, and one lighter which had previously passed through the stomach, and engaged in the descending colon was detected (Figure 2). During laparotomy an induration caused by multiple number of lighters were detected on palpation. A dilated stomach was observed. A nearly $2 \mathrm{~cm}$-long gastrotomy incision was made on the anterior surface of the antrum, and 10 lighters each measuring $8 \times 2 \mathrm{~cm}$ were extracted through this incision (Figure 3). Small bowel, and colon were explored in detail. One lighter in the descending colon was manually milked away from the anal canal. After confirmation of absence of any foreign object by using intraoperative fluoroscopy, gastrotomy defect was closed in two layers. On the postoperative second day oral

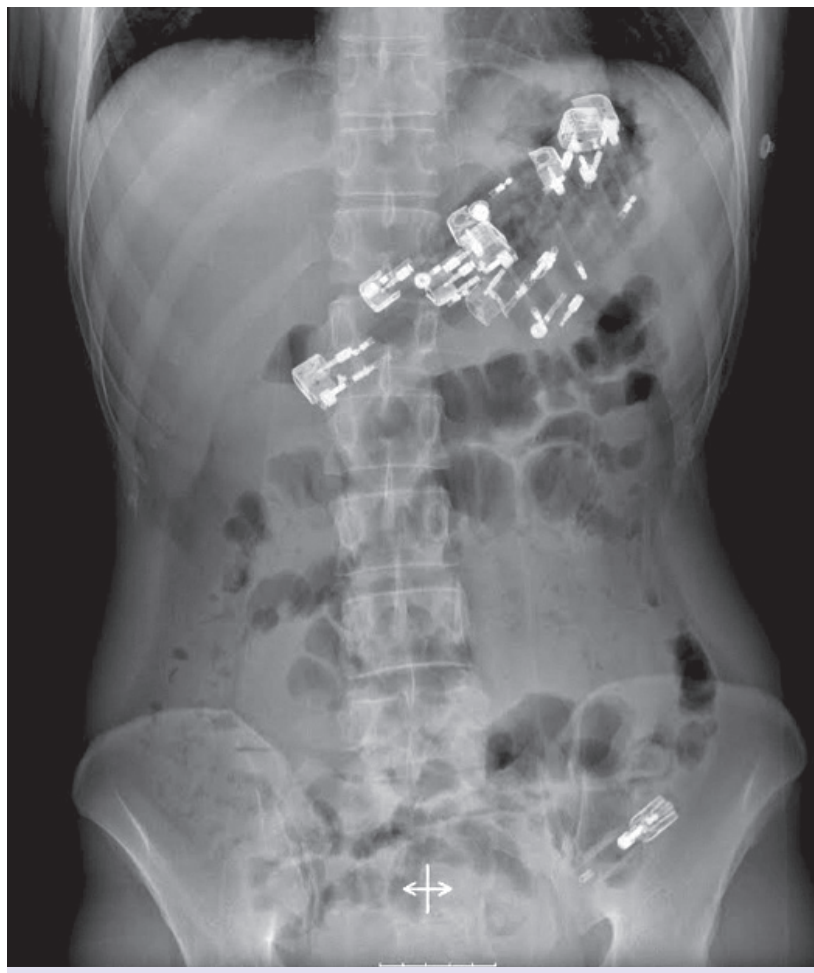

FIGURE2. One lighter in the descending colon.

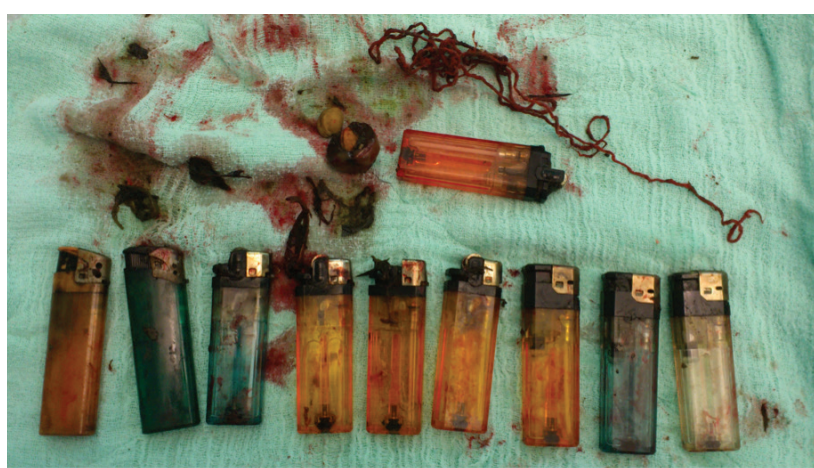

FIGURE 3. Ten lighters extracted from inside the stomach.

intake was started, and the patient was discharged with cure on the postoperative $5^{\text {th }}$ day.

\section{DISCUSSION}

Ingestion of foreign object frequently occurs accidentally during intake of oral food. In most of the cases, ingredients of food, and bony particles are detected. In elder people, dental prostheses, and in mentally retarded people, and psychiatric patients frequently multiple number of atypical objects are observed $[1,3]$. 
In psychiatric patient group, self-inflicting behaviours are observed. In this condition, with potential recurrences, patient does not either intend to commit suicide or consciously try to injure him/herself. Since most of the patients do not mention swallowing a foreign object, diagnosis is usually delayed, and complications increase. Generally multiple number of various kinds of foreign objects are swallowed $[2,4]$. Mother of this patient said that her son had swallowed a metal coin two years ago. Besides, he had swallowed more than two foreign objects.

Clinical picture, and treatment approach change according to the shape, size, number, and level of the foreign object. Since most of the foreign objects are radiopaque, plain abdominal radiography is priorly resorted imaging modality which provides information about the number, size, and location of the foreign object. Still, endoscopy can be used at the same time for diagnostic purposes. However, computed tomography is used in the presence of complications, and in the identification of radiolucent foreign objects which can not be visualized using plain radiograms [5]. In our case, for initial diagnosis plain radiogram was used, then endoscopy was applied to make a definitive diagnosis.

In $80-90 \%$ of the cases, swallowed foreign objects are eliminated naturally through gastrointestinal tract without any complication [3]. Twelve percent of the swallowed foreign objects cannot pass through pylorus, and stuck in the stomach. In cases with obstruction, and intake of sharp objects which cause penetrating-stab injuries, and also large objects (width $>2 \mathrm{~cm}$, and length $>6 \mathrm{~cm}$ ) which presumably cannot be eliminated through gastrointestinal tract, endoscopic intervention should be preferred as the first-line treatment with its higher success, and lower complication rates $[6,7,8]$. Long, solid, and rigid objects can cause gastric outlet obstruction, and by adhering to the gastrointestinal mucosa can induce ulcerations, bleeding, and perforation. Since liquid in the lighters contains toxic chemicals as benzene, butane, hexamine, and propane, and lighters are rigid objects measuring generally more than $6 \mathrm{~cm}$ in length, their extraction is recommended [3, 6]. Especially, in children, and patients with psychiatric disorders, longer duration of endoscopic intervention, and incompliance of the patient require an effective sedation, and intubation is recommended in case of need. In experienced hands, and in the presence of adequate equipment, endoscopic extraction procedures have a $95 \%$ success rate $[7,8,9]$.

Scarce number of foreign objects require surgical treatment. In cases with perforation, obstruction, internal fistulas, abscess, and failed endoscopic interventions, surgical treatment is performed. Type of the surgical procedure differs according to potential complication, and location of the foreign objects $[5,10]$. In our case multiple number of lighters which obstructed gastric outlet were tried to be removed using endoscopic interventions. However, because of injury of the esophageal mucosa, and multiple number of lighters swallowed, endoscopic procedures failed, and the patient underwent open gastrotomy so as to extract 10 lighters.

In conclusion, in cases evaluated because of swallowing multiple number of foreign objects, before surgical operation, radiograms should be obtained if radiopaque objects are identified. Intraoperative exploration should be performed, if the foreign object is radiopaque, in case of need, fluoroscopic examination should be carried out to confirm that all foreign objects are removed completely. Especially, as was the case in our patient, in patients with psychiatric disorders, it should not be forgotten that multiple number of foreign objects might be swallowed at various time points.

Conflict of Interest: No conflict of interest was declared by the authors.

Financial Disclosure: The authors declared that this study has received no financial support.

\section{REFERENCES}

1. Erbil B, Karaca MA, Aslaner MA, Ibrahimov Z, Kunt MM, Akpinar E, et al. Emergency admissions due to swallowed foreign bodies in adults. World J Gastroenterol 2013;19:6447-52.

2. Mutlu H, Aydın B: Ölüm nedeni 41 lira, 32 kuruş: Bir olgu. Anadolu Psikiyatri Derg 2014;15:89.

3. Trgo G, Tonkic A, Simunic M, Puljiz Z. Successful endoscopic removal of a lighter swallowed 17 months before. Case Rep Gastroenterol 2012;6:238-42.

4. Petrea S, Brezean I. Self-ingested intraduodenal foreign bodies- expectancy or surgical sanction? J Med Life 2014;7:421-7.

5. Ricci S, Massoni F, Schiffino L, Pelosi M, Salesi M. Foreign 
bodies ingestion: what responsibility? J Forensic Leg Med 2014;23:5-8.

6. Bektaş A, Bahar K, Özkan H, Yurdaydın C, Özşahin T, Karayalçın S. Foreign bodies in gastrointestinal tract: A case report. Turk J Gastroenterology 1998;1: 81-4.

7. Sugawa C, Ono H, Taleb M, Lucas CE. Endoscopic management of foreign bodies in the upper gastrointestinal tract: A review. World J Gastrointest Endosc 2014;6:475-81.

8. Emara MH, Darwiesh EM, Refaey MM, Galal SM. Endoscopic removal of foreign bodies from the upper gastrointestinal tract: 5-year experience. Clin Exp Gastroenterol 2014;7:249-53.

9. Katsinelos P, Kountouras J, Paroutoglou G, Zavos C, Mimidis $\mathrm{K}$, Chatzimavroudis G. Endoscopic techniques and management of foreign body ingestion and food bolus impaction in the upper gastrointestinal tract: a retrospective analysis of 139 cases. J Clin Gastroenterol 2006;40:784-9.

10. Petrea S, Brezean I. Self harm through foreign bodies ingestion rare cause of digestive perforation. J Med Life 2014;7:246-53. 